\title{
Urban data and city dashboards: Six key issues
}

Rob Kitchin ${ }^{1}$ and Gavin McArdle ${ }^{2}$

1. NIRSA, Maynooth University, Ireland. Rob.Kitchin@ nuim.ie

2. UCD School of Computer Science at University College Dublin, Gavin.McArdle@ucd.ie

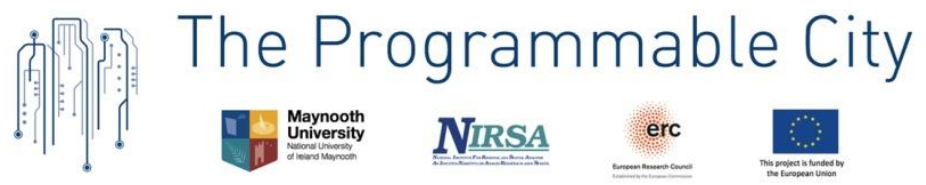

The Programmable City Working Paper 21 http://progcity.maynoothuniversity.ie/

1 Sept 2016

This paper is a pre-print of a chapter that will be published in Kitchin, R., Lauriault, T.P. and McArdle, G. (eds) (forthcoming) Data and the City. Routledge, London.

Published as an open access pre-print on SocArXiv: https://osf.io/k2epn/

\begin{abstract}
This chapter considers the relationship between data and the city by critically examining six key issues with respect city dashboards: epistemology, scope and access, veracity and validity, usability and literacy, use and utility, and ethics. While city dashboards provide useful tools for evaluating and managing urban services, understanding and formulating policy, and creating public knowledge and counter-narratives, our analysis reveals a number of conceptual and practical shortcomings. In order for city dashboards to reach their full potential we advocate a number of related shifts in thinking and praxes and forward an agenda for addressing the issues we highlight. Our analysis is informed by our endeavours in building the Dublin Dashboard.
\end{abstract}

Key words: dashboards, cities, access, epistemology, ethics, open data, scope, usability, utility, veracity, validity 


\section{Introduction}

In this chapter we examine six key issues with respect to how we come to know and manage cities through urban data and city dashboards. In effect, we seek to answer six related questions:

- How are insight and value derived from city dashboards?

- How comprehensive and open are city dashboards?

- To what extent can we trust city dashboards?

- How comprehensible and useable are city dashboards?

- What are the uses and utility of city dashboards?

- How can we ensure that dashboards are used ethically?

We start, however, by answering a more prosaic question: what are city dashboards?

City dashboards use visual analytics - dynamic and/or interactive graphics (e.g., gauges, traffic lights, meters, arrows, bar charts, graphs), maps, 3D models and augmented landscapes - to display information about the performance, structure, pattern and trends of cities. In effect, key data about cities - related to urban systems and infrastructure, society, economy, environment, population, etc. - are displayed on a screen, updated as new data are released and, in many cases, can be interacted with (e.g., selecting, filtering and querying data; zooming in/out, panning and overlaying; changing type of visualisation or simultaneously visualising data in a number of ways) (see Figure 1). In some cases, key data are 'consolidated and arranged on a single screen so the information can be monitored at a glance' (Few 2006: 34). Here, a city dashboard operates like a car dashboard or plane cockpit display providing critical information in a single view (Dubriwny and Rivards 2004; Gray et al. 2014). Analytical dashboards are more extensive in scope and are hierarchically organised to enable a plethora of interrelated dashboards to be navigated and summary-todetail exploration within a single system (Dubriwny and Rivards 2004). Both types of dashboard are common in urban control rooms, but they are also increasingly being displayed in mayor's offices, public buildings, and made accessible to the general public via dedicated websites.

Typically city dashboards display five kinds of data. First, public administration data generated by local government, state agencies and government departments. Second, official statistical data typically generated through surveys (e.g., a census or household/business 
surveys) administered by a national statistical institution or compiled from public administration data. Third, operational data concerning the delivery of services by local government or specific agencies (e.g., a transport provider). Fourth, scientific data relating to environmental conditions (e.g., weather, water levels, pollution, noise). Fifth, derived data that is, data that are created by combining and analysing the other four types of data (e.g., composite indicators, forecasts/predictions). Typically, most data within city dashboards especially of the analytical variety - are traditional in their ontology. That is, they are sampled data generated on a set schedule (e.g., monthly, annually). Increasingly, however, city dashboards are incorporating big data, especially with respect to operational and scientific data. That is, data that are produced in real-time by sensors, actuators, meters, transponders, cameras, and computational devices, but also through crowdsourcing and locative and social media.

\section{Figure 1: City dashboards}
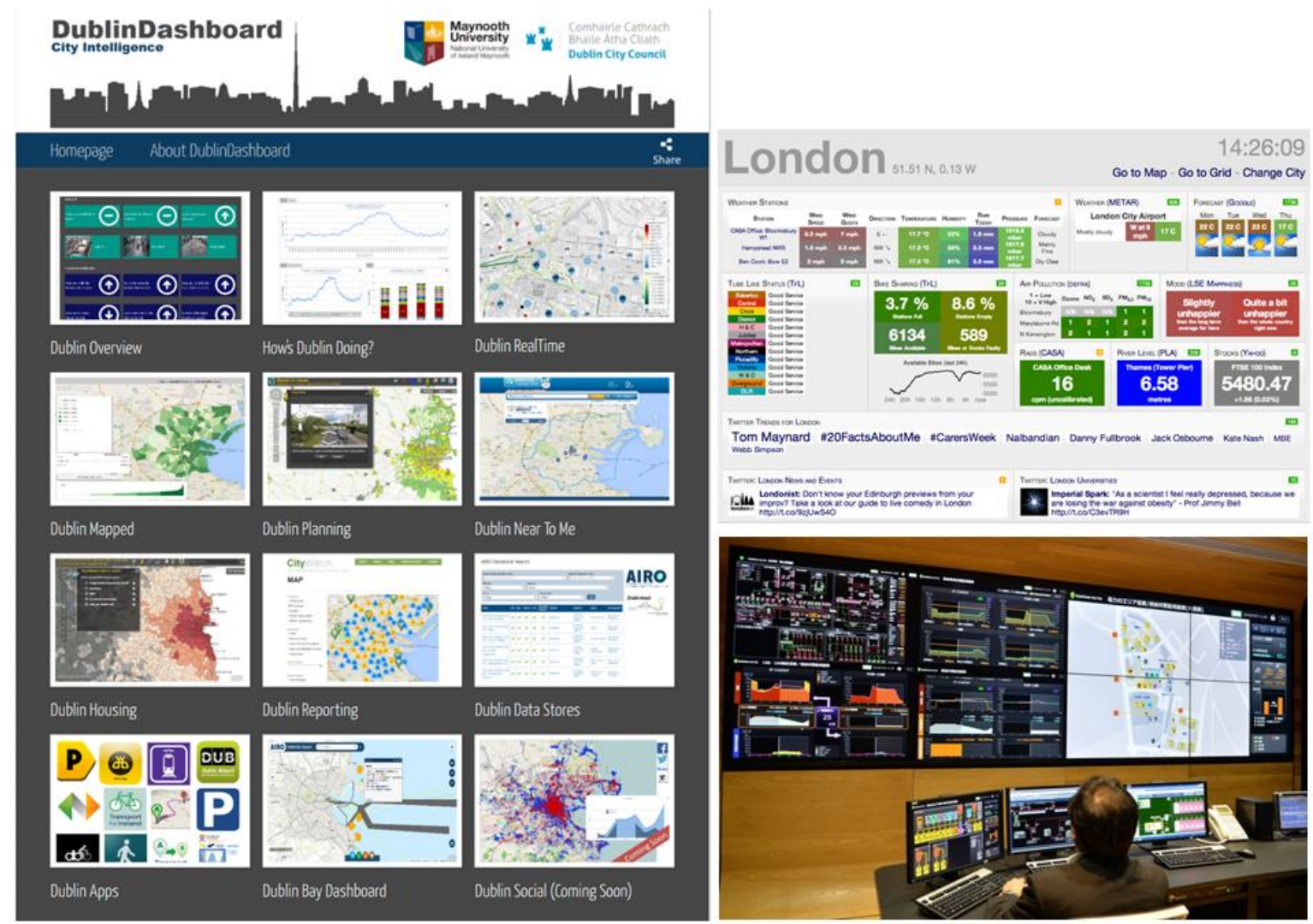

Dublin (http://www.dublindashboard.ie), London (http://citydashboard.org/london/), Kashiwa city [Tokyo] (http://www.citymetric.com/horizons/big-tech-firms-are-wrong-we-must-build-smart-cities-ground-1590) 
The use of urban indicator and city dashboard projects have grown in use since the early 1990s driven by: the sustainability goals of the United Nations Conference on Environment and Development (UNCED) in Rio de Janeiro in 1992 and in particular Chapter 40 of Agenda 21 that advocated the use of indicators to track progress; the rise of new managerialism and the desire to reform the public sector management of city services; citizen and funder demands for evidence-based decision-making and greater accountability and transparency; and the development of smart city initiatives that seek to develop data-driven urbanism (Innes and Booher 2000; Holden 2006; Behn 2014; Kitchin et al. 2015). City dashboards are becoming increasingly popular with city governments and agencies because they collate diverse sets and streams of indicator and big data into one system and provide tools to visualize, query and analyze them. They thus enable a user to gain a 'span of control' over a large amount of varied and quickly transitioning data (Brath and Peters 2004). In particular, they allow a user to track and compare over time and space, and in the case of realtime data the here-and-now of, different phenomena. As such, they permit the following questions to be answered: how is the city performing with respect to key concerns? what are the spatial/temporal patterns of different phenomena? how do different parts of the city compare or how does a city compare with other cities? what is happening in the city right now? Dashboards are thus seen as providing - in a quick and effective manner - key information and insights for delivering and improving services, formulating policy, and undertaking long-term planning. Moreover, dashboards provide other useful tools, such as the exporting of visualisations for use in documents, or sharing via social media, or accessing the underlying data for importing into other analytical packages.

To date city dashboards have received little critical attention ${ }^{1}$. In the remainder of this chapter we consider the epistemology, scope and access, veracity and validity, use and utility, usability and literacy, and ethics of city dashboards. Our analysis draws on an engagement with the wider literature and our own experiences of building the Dublin Dashboard, an analytical dashboard for the city.

\section{Epistemology}

What are the underlying scientific assumptions of city dashboards? How do dashboards work to generate insight and value dashboards? These are epistemological questions. Dashboards utilise visualisations and visual analytics in order to make data about a city legible and interpretable. Visualizations have long been used to summarize and describe datasets because they effectively reveal and communicate the structure, pattern and trends of data and 
their interconnections. Digital visualisations can also be used to navigate and query data, enabling users to gain an overview of the entire dataset, zoom in on items of interest, filter out uninteresting data, select and query an item or group of data, view relationships among data, and extract sub-collections (Shneiderman 1996). These actions are particularly useful for making sense of very large datasets, revealing structure, clusters, gaps, and outliers that might otherwise remain hidden. Visualisations can also be used as a form of analytical reasoning. Here, a visualisation is not simply describing or displaying the data, but is used as a visual analytical tool to extract information, build visual models and explanation, and to guide further statistical analysis (Keim et al. 2010). Often several different types of visual graphics are used in conjunction with each other so that the data can be examined from more than one perspective simultaneously. In addition, data mining and statistical modelling, such as prediction, simulation and optimisation, can be performed and outputted through visual interfaces and outputs (Thomas and Cook 2006). In the context of city dashboards, this use of visual analytics is framed within the emerging field of urban informatics (the extraction and communication of urban information; Foth et al., 2009), but is also informed by urban science (a computational modelling and simulation approach to understanding, explaining and predicting city processes; Batty 2013).

Visual analytics, urban informatics and urban science - and thus city dashboards adopt a realist epistemology that supposes the existence of an external reality which operates independently of an observer and which can be objectively and accurately measured as quantitative data and be tracked, statistically analysed, modelled and visualised to reveal the world as it actually is. In other words, urban data can be abstracted from the world in neutral, value-free, objective and mechanical ways and are understood to be essential in nature; that is, fully representative of that which is being measured (they faithfully capture its essence and are independent of the measuring process) (Desrosieres 1998; Porter 1995). And these data when analysed in similarly objective ways reveal the truth about cities. As such, dashboards have scientific utility because they seemingly translate the messiness and complexities of cities into rational, detailed, systematic, ordered forms of knowledge; they enable a city to be known and explained and to assess how it is performing in a neutral, comprehensive and commonsensical manner (Mattern 2014; Kitchin et al., 2015).

Such a framing has been critiqued for being too closely aligned with positivist thinking, being reductionist, mechanistic, atomizing, essentialist, deterministic and parochial, collapsing diverse individuals and complex, multidimensional social structures and relationships to abstract data points and formulae (Mattern 2013). It also wilfully ignores the 
metaphysical aspects of human life which are difficult to capture as data suitable for inclusion in a dashboard and generally ignores the role of politics, ideology, social structures, capital, and culture in shaping cities (Kitchin 2014b). Indeed, they generally deal with facts, not with intangibles, processes, and complex, multi-scalar phenomena, and if used in isolation they decontextualize a city from its history, its political economy, the wider set of social, economic and environmental relations, and its wider interconnections and interdependencies that stretches out over space and time (Craglia et al. 2004; Mori and Christodoulou 2012). As such, urban informatics produce a limited and limiting understanding of cities and how they work, foreclosing what kinds of questions can be asked and how they are answered.

Moreover, it has been contended that city dashboards do not simply present urban data, but actively produce meaning, generating new visions and understandings of a city that re-shape policy formulation and decision-making. As such, a dashboard is not simply a mirror of a city (with varying levels of methodological imperfections and noise), but acts as a translator by setting the forms and parameters for how data are communicated, interpreted and acted upon (Kitchin et al., 2015). This translation is ideologically framed and inherently political, reflecting design decisions framed within its development context (Kitchin et al, forthcoming). Their makers might envisage them as detached, passive, neutral scientific instruments that communicate the world as is (as can best be scientifically measured, processed and analysed), or recognize their issues and practice a form of strategic essentialism, but dashboards are the product of the ideas, instruments, practices, contexts, knowledges and systems used to generate, process and analyze them and they actively frame and do work in the world (Kitchin 2014; Kitchin et al., 2015). They are underpinned by normative assumptions about what should be measured and what should be revealed; they consist of a 'set of conditions, structured relations, that allow certain behaviours, actions, readings, events to occur' (Drucker 2013).

This epistemological critique is not to say that city dashboards do not produce valuable insights or are not useful. As noted above visual analytics do produce interesting knowledge about cities and, as discussed below, this knowledge can be deployed in the management and governance of cities. But it is to say that dashboards are not objective, neutral mirrors of cities and need to be understood as producing a particular kind of knowledge that has a number of shortcomings and silences that need to be appreciated and taken into account. As the following sections document, these limitations extend beyond epistemology. 


\section{Scope and access}

How comprehensive and open are city dashboards? The first part of this question concerns the scope of the data included in a city dashboard. The second concerns the extent to which a dashboard and the data it displays are open to dashboard builders and the wider public.

In general, dashboards process and display factual, quantitative data; that is, data such as counts, rates, monetary value and scientific measurements that are numeric in format. Much of these data are generated recurrently meaning they can be tracked over time/space and are thus termed 'indicator data'. Indicators can be direct in nature (e.g., measuring the phenomenon, such as R\&D spend to reflect investment in innovation) or indirect (e.g. using a proxy, such as the number of patents registered). Composite indicators combine several indicators using a system of weights or statistics to create a single value, recognizing that most phenomena (e.g., social deprivation) are interrelated and multidimensional and cannot be captured through a single measure (Maclaren 1996). Similarly, urban big data are generally structured, recurrent quantitative measures.

The scope of the data that dashboards display is thus limited. This means that there is an enormous amount of information about cities that are not displayed in city dashboards. Indeed, as noted, there is a diverse range of everyday activities, forms of urban living, and the nature of the human urban condition that are difficult to capture as indicator data. To paraphrase a common sentiment in the social sciences: 'all the good stuff cannot be routinely, quantifiably measured ${ }^{2}$. There are also significant gaps and silences in the data that are displayed. Quantified measures are typically narrowly defined, sampled and non-exhaustive (do not represent all people, places, times) and aggregated (variance is suppressed). Even with big data it is important to appreciate that there remains, and will continue to remain, an unevenness in the deployment of technologies that generate them (not everyone has a smartphone or uses smart cards; not every home has access to the internet or a plethora of digitally networked devices; not every street has sensors and cameras, etc.) and their gaze is that of oligopticons (limited views from fixed positions), rather than a panopticon (an allseeing, god's eye view) (Amin and Thrift 2002). Further, those data that are used are strongly shaped by the technologies and instruments (e.g., the quality and calibration of a sensor) used to generate them which prescribe their parameters and form.

A second limitation concerns access and whether the data that are generated are available for re-use. Up until recently all forms of data used within city dashboards have been relatively difficult to access. Government data was typically locked inside institutions and when made available - often at significant cost (and one section of government would 
often charge another for use of its data) - their use was restricted by copyright and licensing arrangements (Kitchin 2014a). This situation is starting to change with the move to open data, though it is clear that the level of openness varies across administrations and places (Lauriault and Francoli, in press). Data generated by private institutions continues to be a valuable asset and is generally not available for use without a license - consequently much of the deluge of urban big data is not available for city dashboards (though some companies enable a limited amount of data to be accessed through an API). And when public institutions are privatised, their data are often similarly privatised and become closed (see Chapter X).

Access to data was a significant issue in the building of the Dublin Dashboard. We conducted a data audit for the city in November 2013 and tried to obtain datasets that would fulfil the 37 indicators deemed necessary to track the sustainability agenda of Dublin City Council (Dublin City Council 2012) and determine whether the city was in a position to apply for ISO:37120 (the ISO standard for city indicators). Of the 37 sustainability indicators only 10 were available at a Dublin City or finer scale on an annual/sub-annual basis (one of which has subsequently become unavailable due to privatisation (water consumption)). With respect to the ISO standard data could only be sourced for 11 of the 100 indicators required (predominately because the data sought was either privately-held or released at an inappropriate temporal/spatial scale). In terms of accessing real-time data, only a handful of datasets were accessible - all from local government and state agencies - and these were mostly limited to just one of the four local authorities. While this situation has improved it is still the case that there are significant gaps or deficiencies in the data displayed in the Dublin Dashboard, which is considered one of the most comprehensive internationally.

Even when data are available there are often issues related to data measurement (e.g., different agencies using alternate instruments, sampling strategies or classification schemes), data formats and media (e.g., data being released in alternate file types or forms difficult to process such as pdfs), metadata (that is, data about the data concerning lineage, characteristics and quality, which are often missing), data standards (e.g., different agencies using alternate data and metadata standards), and modes of sharing (e.g., different forms of API). This can make it tricky to process and manage data and to compile comparable and interoperable datasets (Kitchin et al., 2007).

Further, the dashboard itself might not be openly accessible, being used operationally by an organisation but not shared publicly. And in cases where the dashboard is made publicly available, the underlying data might not be open to access for re-use, only being 
presented for viewing/analysis. In some cases this is because the framework data (e.g., base maps) are used under license (which might be the case if the base mapping data is sourced from a national mapping agency) or because the attribute data (e.g., indicators) are.

Similarly, the software used to create the dashboard might be propriety (produced by a company and used under license or provided as a service ${ }^{3}$ ) or be open source. The Dublin Dashboard uses a mix of open and propriety software tools. All of the city dashboards we are aware of have a closed form of development and governance, meaning that how they are formulated and run has limited scrutiny.

\section{Veracity and validity}

To what extent can we trust city dashboards? This question refers to data quality and veracity, the appropriateness of the method used and other methodological issues, and the validity of the analysis produced by and interpretation drawn from a dashboard.

A common warning related to data analysis is 'garbage in, garbage out'. In other words, if the data used in a dashboard has little veracity, then the analysis presented has little validity. All datasets contain instrument and human error and bias; generating data always involves a process of abstraction (capturing particular measurements from the sum of all possible data), representation (converting what is being measured into a readable form; e.g., numbers, a wave pattern, a scatterplot, a stream of binary code, etc.), and often generalisation (e.g., into a set of categories) or calibration (transformation to compensate for suspected error/bias). They are produced and shaped by technical instruments of varying specification and parameters, handling procedures, scientific norms and standards, scientist behaviour and organisational processes. The issue of parameters is important because they determine what and how a phenomenon is measured. While a fact seems immutable it is important to note that they are produced, not simply measured (Bowker and Star 1999). For example, how unemployment is calculated varies across jurisdictions and changes over time, with each new formula producing a different rate. Calculating the population of a city seems straightforward but varies depending on who are selected for inclusion/exclusion (e.g., seasonal migrants) or where the boundary of the city is drawn. Likewise, altering the relative weightings of data in composite indicators can have a profound effect on the resulting score (Gruppa and Mogee 2004). There are then with every dataset concerns about data veracity and quality and how accurately (precision) and faithfully (fidelity) the data represent what they are meant to (especially when using samples and proxies), and how clean (error and gap free), untainted (bias free), and consistent (few discrepancies) the data are (Goodchild 2009, Kitchin 2014b). 
Ideally, these concerns should be minimized through well designed and tested processes of data generation and handling and be documented so that others using the data are aware of any issues. Indeed, the importance of reporting data quality is recognized by all scientific bodies. For example, the International Cartographic Association (ICA) details seven key data quality metrics that should be documented in relation to spatial data (which are often used in city dashboards) (Guptill and Morrisson, 1995):

Lineage: The history of the data including details of the source material and any transformations or processes applied in order to produce the final data.

Positional Accuracy: An indication of the horizontal and vertical accuracy of the coordinates used in the data, both to absolute and relative locations. It must account for the processes applied to the data which are described by the lineage.

Attribute Accuracy: The accuracy of the quantitative and qualitative data attached to the spatial data.

Completeness: The degree to which spatial and attribute data are included or omitted from the datasets. It also describes how the sample is derived from the full population and presents the spatial boundaries of the data.

Logical Consistency: The dependability of relationships within the spatial data.

Semantic Accuracy: The quality with which geographical objects are described in accordance with the selected model. Semantic accuracy refers to the pertinence of the meaning of the geographical object rather than its geometry.

Temporal Data: The date of observation, the type of update and the validity period for the data.

Data quality issues are also mandated by several ISO standards, such as ISO 19115-1:2014 and 19157:2013. These standards do not indicate acceptable thresholds for quality data, but rather mandate the metadata that needs be generated with respect to data veracity in order to receive the standard (McArdle and Kitchin, 2016).

Nonetheless, despite big data being known to be messy and dirty in nature (MayerSchonberger and Cukier 2013), some have argued that using big data does not require the same standards of data quality and veracity as traditional data because the exhaustive nature of the dataset removes sampling biases and compensates for any errors or gaps or inconsistencies in the data or weakness in their fidelity. For example, Mayer-Schonberger and 
Cukier (2013: 13) contend that 'more trumps better'. Helland (2011) suggests that with very large datasets ' 'good enough' is good enough'. And Franks (2012: 211) argues that big data just needs to be 'clean-enough data'. But what is good-enough or clean-enough data? And can we trust such data to underpin critical decisions about city policy and investments? What we really require is big data to have the same levels of veracity as traditional datasets, to have and comply with their own ISO standards, and for this information to be available as metadata. At present, it is difficult to establish the veracity of much urban big data, which are being shared with undocumented errors, absences and biases.

In fact, it is difficult to establish the veracity of much of the data that are made available through open data sites and displayed in city dashboards. This is because either data used in city dashboards have no data quality metadata, or such metadata is not made available. The open data portals for London, Paris and Dublin, and the World Council of City Data ${ }^{4}$ (253 cities in 80 countries), only provide data source and timeliness information and not general nor specific measures of data quality (McArdle and Kitchin 2016). Nor do they detail the process through which raw data is translated (e.g., cleaned, manipulated, transformed) for publication. Similarly, the Dublin Dashboard includes no metadata beyond source and timeliness. One is simply asked to trust that the data has veracity and validity.

One is also simply asked to trust that the visual analytics and any calculations and modelling undertaken are valid. As most methods textbooks highlight, it is relatively straightforward to either unintentionally or deliberately lie or mislead with statistics and maps. How data are transformed and presented can make a significant difference to how they are interpreted. Ecological validity concerns the legitimacy of making inferences based on the outputs presented. One of the most common types of ecological fallacy created within city dashboards is the Modifiable Areal Unit Problem (MAUP) (Openshaw 1984), wherein the statistical geography used to display aggregate data can have a marked effect on the pattern of observations. For example, Figure 2 displays the same unemployment data in three statistical geographies, producing varying patterns and interpretation. Likewise, altering the classification boundaries, or altering the number of classes, can have a similar effect. In other words, it is possible to draw very different conclusions depending on how the data are aggregated and presented. Similarly, the choice of analytics and models, and the selection and tweaking of parameters within them, can produce markedly different results. Yet how a calculation or model is formulated is often black boxed meaning that its workings are not made available to others to assess or to replicate. In these cases, users are again asked to trust that the analytics are producing valid analysis which leads to sensible interpretation. 
Figure 2: Mapping the same data at three different administrative scales
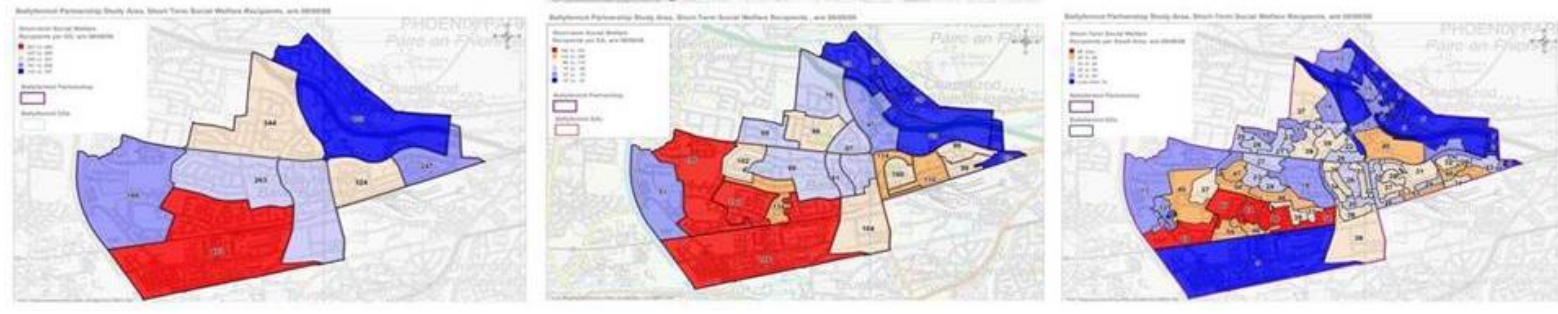

\section{Useability and literacy}

How comprehensible and useable are city dashboards? There is an assumption that city dashboards - especially those that are publicly available - enable a suite of urban data to be explored, analyzed and interpreted in an easily digestible and intuitive way without the need for specialist skills or knowledge. In part this is because the systems are point and click in nature and require no knowledge of how to produce interactive, dynamic graphics, maps or analytics. There are three issues here - navigation of site, use of tools, and data/analytics literacy.

For a city-at-a-glance dashboard navigation is straightforward. However, for an analytical dashboard that contains a number of modules navigation around the site and finding pertinent data and analysis can be more tricky. The Dublin Dashboard, for example, has 56 sub-modules at the time of writing, some that utilise hundreds of data variables (e.g., census mapping modules). At present, there is no detailed site map or data directory. There is also no deep sense of navigation, search and browse issues as there has been no detailed user-testing. In terms of the tools presented, the Dublin Dashboard utilises a number of different software data visualization and mapping programmes. These are configured in particular ways and present the user with a series of drop-down menus, buttons, check boxes, graphics and maps that can be interacted with (e.g., select for more info, zoom). It is sometimes not at all clear how to display data, change to new data layers, perform analysis, interact with data, etc. Nor are there any user guides to explain how to undertake different tasks. Again, there has been no user requirement or user testing analysis. This is not uncommon for city dashboards or open data sites. What this means is that city dashboards provide a sub-optimal experience for users and their full utility is not being realised.

There is also an issue of data and analytics literacy. Dashboards assume that their users understand what data are being presented (and to take into account issues of formulation, error/bias, etc.), can make sense of and validly interpret various forms of 
visualization and maps, and understand any analytics being undertaken. This, however, is not the case and data and analytic literacy is highly variable across the general public, but also specialist users such as planners and policy makers. This is especially the case for analytics such as modelling where it is not clear how the model is calculated or what the output means. For example, in the case of Boston's City Score ${ }^{5}$ the user is presented with a table of numbers, updated daily, that denote how well the city is performing in relation to a number of tasks (Figure 3). In the accompanying text the viewer is told that a number above 1 means a target is being exceeded, whereas below 1 the service is deficient and will be reviewed.

However, there is no detailed information on what the tasks being monitored are, with several unexplained acronyms, and no information on the form and veracity of underlying data or how the scores are calculated and targets set. It is therefore quite difficult to interpret the information presented. Similarly, the Dublin Dashboard does little to compensate for weak data and analytics literacy.

Figure 3: Boston City Score

\begin{tabular}{|c|c|c|c|c|}
\hline \multirow[t]{2}{*}{$\begin{array}{l}\text { LEGEND } \\
<\text { I (FOLLOW UP) } \\
=\text { I (MAINTAINING) } \\
>\text { I (EXCEEDING) }\end{array}$} & \multicolumn{2}{|c|}{ MAYOR MARTIN J. WALSH } & \multicolumn{2}{|r|}{$\begin{array}{l}\text { LAST UPDATED } \\
4 / 612016\end{array}$} \\
\hline & DAY & WEEK & MONTH & QUARTER \\
\hline STABBINGS (TREND) & 2.50 & 1.17 & I.6I & 1.58 \\
\hline LIBRARY USERS & 1.81 & 1.82 & I.7I & 1.67 \\
\hline PART I CRIMES & 1.80 & 1.36 & 1.34 & 1.40 \\
\hline ON-TIME PERMIT REVIEWS & 1.28 & 1.14 & 1.15 & 1.12 \\
\hline MISSED TRASH ON-TIME $\%$ & 1.25 & 1.25 & 1.25 & 1.22 \\
\hline PARKS MAINTENANCE ON-TIME $\%$ & 1.25 & 0.86 & 0.88 & 0.92 \\
\hline SIGN INSTALLATION ON-TIME \% & I. 25 & 1.22 & 1.14 & 1.07 \\
\hline TREE MAINTENANCE ON-TIME \% & 1.25 & 1.25 & 1.19 & 1.17 \\
\hline SIGNAL REPAIR ON-TIME $\%$ & 1.20 & 1.12 & 1.09 & 0.99 \\
\hline BFD INCIDENTS & 1.16 & 1.04 & I.II & 1.29 \\
\hline EMS INCIDENTS & 1.06 & 1.01 & 1.03 & 1.07 \\
\hline EMS RESPONSE TIME & 0.99 & 1.05 & 1.03 & 1.03 \\
\hline POTHOLE ON-TIME $\%$ & 0.99 & 0.99 & 0.91 & 0.91 \\
\hline BFD RESPONSE TIME & 0.98 & 0.97 & 0.96 & 0.94 \\
\hline 3II CALL CENTER PERFORMANCE & 0.91 & 0.95 & 0.97 & 0.95 \\
\hline CONSTITUENT SATISFACTION SURVEYS & 0.75 & 0.89 & 0.92 & 0.93 \\
\hline STREETLIGHT ON-TIME $\%$ & 0.75 & 0.84 & 0.98 & 0.96 \\
\hline BPS ATTENDANCE & & 0.97 & 0.96 & 0.97 \\
\hline GRAFFITI ON-TIME $\%$ & & 1.16 & 1.18 & 1.19 \\
\hline HOMICIDES (TREND) & & & 4.60 & 4.48 \\
\hline
\end{tabular}

\section{Uses and utility}

What are the uses and utility of city dashboards? In the main, city dashboards are used in three main ways: for monitoring performance and managing urban services; for contextually understanding and formulating policy; and for creating public knowledge and producing counter-narratives. In addition, they can be used tactically (e.g., for delaying a strategy, 
substitute for action, deflect criticism), symbolically (e.g., to provide reassurance or place promotion), politically (e.g., ammunition to support a particular position) (Hezri 2004), and if the data within them are open they can help facilitate and promote an open data economy.

The realist epistemology that underpins the logic and workings of city dashboards promotes an instrumental rationality in which cities can be steered and managed through a set of data levers and analytics and that urban issues can be solved through a range of technical solutions (Mattern 2013; Morozov 2013; Kitchin et al, 2015). Here, city dashboards are used to: monitor and guide operational and policy practices with respect to specified targets; provide evidence of the success or failure of programmes and policies; discipline and reward performance; guide the development of new strategies; and shape spending patterns (Craglia et al. 2004; Franceschini et al. 2007; Behn 2014). An example of such an approach is Baltimore's use of CitiStat. Every week the mayor and city managers meet in a specially designed room using dashboards to review performance and set new targets for the city as a whole and for each department (Gullino 2009). This approach has been adopted in whole or part (e.g., Boston's City Score) by a number of other US cities. For critics, this instrumental rationality promotes a technocratic form of governance that: forecloses other modes of governance and other forms of knowledge (such as phronesis - knowledge derived from practice and deliberation; and metis - knowledge based on experience) (Parsons 2004); fails to recognize that cities are complex, multifaceted, contingent, relational systems, full of contestation and wicked problems that are not easily captured or steered (Kitchin et al. 2015); and that urban issues are often best solved through political/social, public policy, and public investment solutions and citizen-centred deliberative democracy rather than technical fixes (Greenfield 2014; Kitchin 2014b).

In contrast, some municipalities use dashboards in a more contextual way. Here, it is recognized that cities are not mechanical systems that can be disassembled into its component parts and fixed, or steered and controlled through data levers. Instead, systems and governance are understood as complex and multi-level in nature, and the effects of policy measures are diverse and multifaceted, and neither is easily reducible to targets and performance metrics (Van Assche et al. 2010). Indicators highlight trends and potential issues, but do not show their causes or prescribe answers. Conceived in this way city dashboards provide useful contextual data - that can be used in conjunction with other data and initiatives - but are not used in a strongly instrumentalist, mechanistic way to direct management practices (Kitchin et al., 2015). A long standing example of such an approach is that employed within Flanders, Belgium, where since the late 1990s a number of cities have 
employed a common City Monitor for Sustainable Urban Development, consisting of nearly 200 indicators, to provide contextual evidence for policy making (Van Assche et al. 2010). The Dublin Dashboard follows this model. Nonetheless, in both managerial and contextual uses of dashboards, they are viewed as providing a stronger evidential base for city management than anecdote and occasional studies.

In cases where a city dashboard is publicly accessible it is hoped that it provides the same kinds of utility as open data in general - that is, it enables transparency, accountability and participation by providing the public with the data and the tools to extract insight and value from these data (Kitchin 2014a). In other words, it allows citizens to evaluate the work of city agencies in providing services and managing and governing the city, and it allows them to take an active role in contributing to evidence-informed debate and policy making and to produce counter-narratives to those produced by authorities and other vested interest groups. Here, open city dashboards work to democratise the ability to produce information and knowledge, rather than the power of data being confined to its producers and those in a position to pay for data and tools.

\section{Ethics}

How can we ensure that dashboards are used ethically? There has been a lot of concern with respect to the generation and use of personally identifiable information (PII) in the big data age, including those generated by smart city technologies (Edwards 2016; Kitchin 2016). However, city dashboards display aggregate and anonymous data or data that concerns a system rather than people. As such, ethical issues related to PII, such as individual level privacy and predictive privacy harms, are generally not pertinent. That is not to say that there are no ethical issues arising from city dashboards.

The data within city dashboards can be used to construct place profiles and histories that can be used as the basis for the social and spatial sorting of places and communities. Indeed, there is a multi-billion dollar geodemographics industry that does precisely this, using place profiles to geo-target advertising/marketing and private investment and to calculate insurance premiums and online prices (Goss 1995; Harris et al. 2005) ${ }^{6}$. Similarly, place profiles can be used by the public sector to determine which areas should receive placetargeted investment, additional policing, or differential service provision. The data can also be used to discriminate areas of blight and problems and to reinforce territorial stigma, effecting public perception and affecting local community cohesion (Slater 2016). In other words, the data and tools in dashboards can be used to treat places and the populations within 
them differentially in ways that can be discriminatory and affect quality of life. It is therefore important to consider the ways in which city dashboards are used and to consider whether their use is fair, equitable or prejudiced and how any issues might be addressed.

\section{Conclusion}

In this chapter we have sought to document a number of key issues and questions with respect to the production and use of city dashboards. While we have provided a critical assessment that challenges some of the dominant thinking with respect to city dashboards, urban informatics and visual analytics, we also believe that dashboards provide useful insights and have much utility. Indeed, we have invested much time and effort into building the Dublin Dashboard and working with Dublin's open data portal, Dublinked, and other data providers, and we are about to build a dashboard for another city, Cork.

What is required, we believe, for city dashboards to reach their full potential as a smart city technology that can help produce more efficient, equitable, sustainable and resilient cities is a number of related shifts in thinking and praxes. First, there has to be a shift in the underlying epistemology of city dashboards to recognize that they conceive the urban in a particular way and seek to understand and explain the city using an approach which produces delineated and situated knowledge rather than communicating objective, scientific truths. Second, limitations with respect to the scope of data and accessing datasets need to be documented and also tackled by working with agencies and companies to open key datasets. Third, significant work needs to be undertaken to establish the veracity and validity of datasets and analytics and dashboards need to be populated with appropriate metadata. Fourth, the usability of city dashboards in general and each specific tool needs to be established through user testing, as well as methods to improve user experience, and training and education tools to aid and improve data/analytics literacy need to be developed and included in dashboards. Fifth, the instrumental rationality of city dashboards needs to be reconceived, with dashboards always used in conjunction with other forms of knowledge and other modes of governance when evaluating, managing and formulating the delivery city services and policy. And lastly, the ethics and potential harmful uses of using city dashboards need to be further examined and strategies developed to minimize any harms.

While this list is by no means comprehensive it provides an initial agenda for addressing the issues we have discussed. This shift in thinking, will allow urban dashboards to reach their full potential and align them with the vision of the Open Knowledge Foundation $^{8}$ who state that: 'Open knowledge is what open data becomes when it's useful, 
usable and used - not just that some data is open and can be freely used, but that it is useful accessible, understandable, meaningful, and able to help someone solve a real problem'. Moreover, this agenda will provide useful insights for considering the wider relationship between data and the city.

\section{Acknowledgements}

The research for this chapter was funded by a European Research Council Advanced Investigator grant, The Programmable City (ERC-2012-AdG-323636), and a Science Foundation Ireland grant, Building City Dashboards (15/IA/3090). The chapter draws extensively on three previously published papers: Kitchin, R., Lauriault, T.P. and McArdle, G. (2015) Knowing and governing cities through urban indicators, city benchmarking and real-time dashboards. Regional Studies, Regional Science 2: 1-28. McArdle, G. and Kitchin, R. (2016) Improving the veracity of open and real-time urban data. Built Environment 42(3): 446-462. Kitchin, R., Maalsen, S. and McArdle, G. (forthcoming) The praxis and politics of building urban dashboards. Geoforum, published as a pre-print working paper at http://ssrn.com/abstract=2608988.

\section{Notes}

1. Though see Kitchin et al. (2015), Kitchin et al. (forthcoming), Mattern (2015).

2. For example, see Yanis Varoufakis: All the good stuff that cannot be measured https://www.youtube.com/watch?v=FqZ2evtU0Yg

3. For example, Socrata provide an open data dashboard service for cities.

4. See http://data.london.gov.uk/, http://opendata.paris.fr/, http://www.dublinked.ie/, http://open.dataforcities.org/.

5. https://www.boston.gov/cityscore

6. A Wall Street Journal investigation found that customers in different locations in a region paid varying prices for the same online goods based on a profile of that location. (Valentino-DeVries et al. 2012)

7. See http://www.dublindashboard.ie

8. See http://okfn.org/about/vision-and-values

\section{References}

Amin, A. and Thrift, N. (2002) Cities: Reimagining the Urban. Polity, London.

Batty, M. (2013) The New Science of Cities. Cambridge, MA: MIT Press.

Behn, R.D. (2014) The PerformanceStat Potential: A Leadership Strategy for Producing. Brookings Institution Press/Ash Center: New York. 
Bowker, G. and Star, L. (1999) Sorting Things Out: Classification and Its Consequences. MIT Press, Cambridge, MA.

Brath, R. and Peters, M. (2004) Dashboard design: Why design is important. DM Direct, October 2004.

Craglia, M., Leontidou, L., Nuvolati, G. and Schweikart, J. (2004) Towards the development of quality of life indicators in the 'digital' city. Environment and Planning B 31(1): 51-64.

Desrosières, A. (1998) The Politics of Large Numbers: A History of Statistical Reasoning translated by Naish, C. Harvard University Press, Cambridge, MA.

Drucker, J. (2013) Performative materiality and theoretical approaches to interface. Digital Humanities Quarterly 7(1).

http://www.digitalhumanities.org/dhq/vol/7/1/000143/000143.html (last accessed 29 August 2016).

Dublin City Council (2012) Sustainability Report 2012: Part B Sustainability Indicators. http://dublincity.ie/sites/default/files/content//WaterWasteEnvironment/Sustainability/Doc uments/SIR2012.pdf (last accessed 29 August 2016)

Dubriwny, D. and Rivards, K. (2004) Are you drowning in BI reports? Using analytical dashboards to cut through the clutter. DM Review, April 2004, http://internal.advizorsolutions.com/press/Cut\%20Through\%20The\%20Clutter.pdf (last accessed 29 August 2016).

Edwards, L. (2016) Privacy, security and data protection in smart cities: A critical EU law perspective. European Data Protection Law Review 2(1): 28-58.

Few, S. (2006) Information Dashboard Design: The Effective Visual Communication of Data. O'Reilly: Sebastopol, CA.

Foth, M. (ed.) (2009) Handbook of Research on Urban Informatics: The Practice and Promise of the Real-Time City. Hershey, PA: IGI Global.

Franceschini, F., Galetto, M., and Maisano, D. (2007) Management by Measurement: Designing Key Indicators and Performance Measurement Systems. Berlin: Springer.

Franks, B. (2012) Taming the Big Data Tidal Wave: Finding Opportunities in Huge Data Streams with Advanced Analytics. Wiley. Hoboken, NJ.

Godin, B (2003) The emergence of S\&T indicators: why did governments supplement statistics with indicators? Research Policy 32: 679-691.

Goodchild, M.F. (2009) Uncertainty, in Kitchin, R. and Thrift, N. (ed) International Encyclopedia of Human Geography. vol. 12: 1-5. Elsevier, Oxford. 
Goss, J. (1995) 'We know who you are and we know where you live': the instrumental rationality of geodemographics systems. Economic Geography 71: 171-198.

Gray, S., Milton, R. and Hudson-Smith, A. (2013) Visualising real-time data with an interactive iPad video wall. Talisman. http://www.geotalisman.org/files/2013/05/MethodsNewsSpring2013_DRAFT_Part7.pdf (last accessed 29 August 2016).

Greenfield, A. (2013) Against the Smart City. New York: Do Publications.

Gruppa, H. and Mogee, M.E. (2004) Indicators for national science and technology policy: how robust are composite indicators? Research Policy 33(9): 1373-1384.

Guptill, S. C. and Morrison, J. L. (eds) (1995) Elements of Spatial Data Quality. Elsevier: Amsterdam.

Harris, R., Sleight, P. and Webber, R. (eds) (2005) Geodemographics, GIS and Neighbourhood Targetting. John Wiley: Chichester.

Helland, P. (2011) If you have too much data, then "good enough" is good enough. ACM Qиеие 9(6).

Hezri, A.A. (2004) Sustainability indicators system and policy processes in Malaysia: a framework for utilisation and learning. Journal of Environmental Management 73(4): $357-371$.

Holden, M. (2006) Urban indicators and the integrative ideals of cities. Cities 23(3): 170183.

Innes, J. and Booher, D.E. (2000) Indicators for sustainable communities: A strategy building on complexity theory and distributed intelligence. Planning Theory \& Practice 1(2): 173186.

Keim, D., Kohlhammer, J., Ellis, G. and Mansmann, F. (2010) Mastering the Information Age - Solving Problems with Visual Analytics. Eurographics Association. http://www.vismaster.eu/book (last accessed 29 August 2016)

Kitchin, R. (2014a) The Data Revolution: Big Data, Open Data, Data Infrastructures and Their Consequences. Sage, London.

Kitchin, R. (2014b) The real-time city? Big data and smart urbanism. GeoJournal 79(1): 114.

Kitchin, R. (2016) Getting smarter about smart cities: Improving data privacy and data security. Data Protection Unit, Department of the Taoiseach, Dublin, Ireland. http://www.taoiseach.gov.ie/eng/Publications/Publications_2016/Smart_Cities_Report_Ja nuary_2016.pdf (last accessed 29 August 2016). 
Kitchin, R., Lauriault, T.P. and McArdle, G. (2015) Knowing and governing cities through urban indicators, city benchmarking and real-time dashboards. Regional Studies, Regional Science 2: 1-28.

Kitchin, R., Maalsen, S. and McArdle, G. (forthcoming) The praxis and politics of building urban dashboards. Geoforum, published as a pre-print working paper at http://ssrn.com/abstract=2608988.

Lauriault, T.P. and Francoli, M. (in press) Openness, transparency, participation. In Kitchin, R., Lauriault, T.P. and Wilson, M.W. (eds) Understanding Spatial Media. Sage: London.

Mattern, S. (2013) Methodolatry and the art of measure: The new wave of urban data science. Places Journal. https://placesjournal.org/article/methodolatry-and-the-art-of-measure (last accessed 29 August 2016).

Mattern, S. (2014) Interfacing urban intelligence. Places Journal. https://placesjournal.org/article/interfacing-urban-intelligence (last accessed 29 August 2016).

Mattern, S. (2015) Mission control: A history of the urban dashboard, Places Journal. https://placesjournal.org/article/mission-control-a-history-of-the-urban-dashboard (last accessed 29 August 2016).

Maclaren, V. W. (1996) Urban sustainability reporting, Journal of the American Planning Association, 62(2).

Mayer-Schonberger, V. and Cukier, K. (2013) Big Data: A Revolution that will Change How We Live, Work and Think. John Murray, London.

McArdle, G. and Kitchin, R. (2016) Improving the veracity of open and real-time urban data. Built Environment 42(3): 446-462

Mori, K. and Christodoulou, A. (2012) Review of sustainability indices and indicators: Towards a new City Sustainability Index (CSI). Environmental Impact Assessment Review 32: $94-106$.

Openshaw, S. (1984) The Modifiable Areal Unit Problem. Concepts and Techniques in Modern Geography 38, Geo Books, Norwich.

Parsons, W. (2004) Not just steering but weaving: relevant knowledge and the craft of building policy capacity and coherence. Australian Journal of Public Administration 63(1), 43-57.

Porter, T.M. (1995) Trust in Numbers: The Pursuit of Objectivity in Science and Public Life. Princeton University Press, Princeton, N.J. 
Shneiderman, B. (1996) The eyes have it: a task by data type taxonomy for information visualizations. Proceedings IEEE Visual Languages 96: 336-343.

Slater, T. (2016) Territorial stigmatization: Symbolic defamation and the contemporary metropolis. In Hannigan, J. and Richards, G. (eds) The Handbook of New Urban Studies. London: Sage.

Thomas, J.J. and Cook, K.A. (2006) A visual analytics agenda. IEEE Computer Graphics \& Applications 26: 10-13.

Valentino-DeVries, J., Singer-Vine, J. and Soltani, A. (2012) Websites vary prices, deals based on users' information. Wall Street Journal, December 24, 2012. http://www.wsj.com/articles/SB10001424127887323777204578189391813881534 (last accessed 29 August 2016).

Van Assche, J., Block, T., and Reynaert, H. (2010) Can community indicators live up to their expectations? The case of the Flemish city monitor for livable and sustainable urban development. Applied Research Quality Life 5: 341-352. 